\title{
ПУБЛИЧНАЯ ПОЛИТИКА В США И ЕС: ТЕОРЕТИЧЕСКИЕ ПОДХОДЫ
}

\author{
ЯН КЭ \\ Белорусский государственный университет \\ Минск, Республика Беларусь
}

Аннотация. В статье автор, исследуя развитие основных отраслей публичной политики в Соединенных Штатах и некоторых странах континентальной Европы, раскрывает ее основные характеристики и процессы функционирования в Соединенных Штатах и крупнейших странах ЕС.

Изучены трактовки понятия «публичная политика» представителями различных политических школ, а также проведен комплексный анализ источников, исследующих методологию публичной политики.

В процессе анализа толкования публичной политики в США и ЕС выявлены три подхода к пониманию термина публичная политика: институциональный, деятельностный и академический.

С целью проанализировать и систематизировать основные подходы к пониманию публичной политики, используемые в США и ЕС применялись методы анализа, сравнения и обобщения.

Основная идея подхода, в котором гражданское общество рассматривается как основной элемент публичной политики, заключается в попытке быть вовлеченным в процесс политической жизни своей страны, но не силой внешних факторов, а самосознанием. Так что народ страны сам по себе превращается в политический элемент. В качестве реакции на такое поведение США и ЕС стимулируют граждан к участию в политической жизни. Этот процесс заставляет общество предъявлять высокие требования к публичной политике.

В данной статье представлены результаты описательной и сравнительной характеристики подходов США и ЕС к публичной политике, как обобщенный материал и определены ключевые моменты для реализации определенных подходов в сфере государственного управления.

Ключевые слова: публичная политика; Европа; США; избирательная система; правовые системы; политико-институциональные силы; социальная политика; инновационное развитие.

Образец цитирования: Ян Кэ Публичная политика в США и ЕС: теоретические подходы // Актуальные проблемы международных отношений и глобального развития: сб. науч. статей. Минск, 2021. Вып. 9. С. 289302. https://doi.org/10.33581/2311-9470-2021-9-289-302

Введение. Публичная политика - как политическое понятие относительно молодое. На сегодняшний день существует множество различных интерпретаций и школ, предпринимающих попытки дать 
наиболее точное определение сущностному содержанию этого явления. Поскольку публичная политика является следствием многопарадигмального периода в социальных науках, в настоящее время исследователи сталкиваются множеством дефиниций данного термина. Автор ставит перед собой задачу выявить основные теоретические подходы к пониманию термина «публичная политика». Одновременно изучение основных подходов к пониманию публичной политики в ЕС и США оказывает большое влияние на разработку внутренней и внешней политики КНР.

Цель данной статьи - проанализировать основные подходы понимания публичной политики, используемые в США и ЕС. Автор пытается их систематизировать. В ходе анализа научной литературы можно явно выделить три подхода к пониманию термина «публичная политика»: институциональный, деятельностный и академический.

Методы исследования. При проведении исследования автор опирался на принцип историзма, использовал общенаучные (анализ, синтез, сравнение, обобщение) и специальный исторические подходы (историко-сравнительный, структурный подход, системный подход), также применил метод описательного анализа.

Объектом исследования является публичная политика в США и странах ЕС. Предмет исследования - подходы к пониманию публичной политики.

Обзор литературы по теме. Для написания статьи были изучены и сопоставлены исследования отечественных и зарубежных специалистов по публичной политике. Политический процесс структурирован определенным набором институтов - этот тезис немецкого исследователя М. Риттера был выбран в качестве основной интеллектуальной посылки, как представителя институционального подхода к определению публичной политики. Специалист раскрывает концепцию через призму «демократии участия» [2, с. 3-5], что означает следующее: «Теория демократии» посвящена тому, что постоянное добровольное участие населения в политическом процессе является единственной гарантией сохранения реальной демократии... Построение демократических политических институтов, таких как парламент, правительство, правовые институты, подконтрольные исполнительные органы, не может происходить без участия населения» ${ }^{1}$.

\footnotetext{
${ }^{1}$ Ю Тэнфэй. Мэй го лянь бан чжи ду цуй чжи гуань си дэ янь цзю = Исследование вертикальных властных отношений в Федеральной системе Соединенных Штатов: дис. ...кандидата полит. наук: 23.00.01.Тяньцзинь. 2013. С. 64-66.
} 
Французские политологи Ив Мени и Жан-Клод Тениг отмечают, что, не выходя из зоны деятельностной парадигмы, необходимо начинать говорить о публичной политике не только в связи с действиями властей, но уже с момента определения зоны общественного приоритета (области, которой будет уделено основное внимание) [3, c. 545-566]. Именно наличие такого приоритета определит курс или заложит основу для различных программ действий и создаст определенную систему взаимодействия в рамках распределительной политики (распределение общественных благ).

Важно отметить, что представители австрийской школы экономики довольно скептически относятся к такому взаимодействию между частным сектором, обществом и государством, отмечая, что одно из наиболее ярких проявлений такого взаимодействия - лоббирование. Лоббирование - процесс субсидирования государством неэффективных проектов, которые не могут существовать на практике и не могут быть реализованы без постоянной поддержки.

Обращая внимание на бум строительства стадионов в США, европейский экономист Дж. Каллахан считает, что правительство тем самым заранее поощряет формирование неэффективных проектов, ведь, давая деньги на эту идею, правительство потенциально лишает ресурсов какую-то другую область, которая могла бы развиваться с помощью этих средств [4, с. 120-125]. Поэтому вопрос о качестве и эффективности принимаемых мер должен занимать особую нишу в научно-практической среде публичной политики.

Сосредоточившись на академическом подходе, следует обратиться к исследованиям в этой области, проведенным русским социологом А. Шматко. Она уделяет особое внимание философским и методологическим аспектам и проблемам. Для ученого публичная политика имеет множество значений в силу ее сложной природы, набора интеллектуальных предпосылок и т. д. [5, с. 110-115]. Научная рефлексия, политическое действие, а также коммуникация в средствах массовой информации являются тремя главными компонентами существующих в симбиозе и итог их - публичная политика. Более того, она, проведенная специалистами в области общественных наук, интеллектуалами, экспертами и журналистами в области политики, изменила содержание последней, сместив акценты в политической сфере в силу ряда исторически обусловленных обстоятельств.

По мнению немецко-американского политического теоретика Х. Арендта, публичная политика представлена в двух ее проявлениях. 
Во-первых, как система превентивных мер и нормативных актов. Вовторых, как совокупность категорий социальных представлений и легитимных номинаций ${ }^{2}$. В краткой форме, они представляют феномен взаимодействия между властями и теми, на кого направлена политика. совокупность информационных и интерпретационных компонентов, иерархию событий социальной жизни, деятельность профессиональных и непрофессиональных субъектов, участвующих в политическом процессе, все виды рефлексивных действий в соответствии с набором выполненных действий [6, с. 377-382].

Публичная политика имеет широкое собирательное значение, вся суть которого сводится к формированию «образа», «контура» современной политики. Иными словами, это форма представления власти, которая может формировать частное, и частное в общественной жизни, а также приводит как к единству, так и к разделению общества $^{3}$. Такое понимание публичной политики также обладает важным коммуникативным потенциалом.

Европейские социологи Н. Луман, Ч. Тилли, Э. Дюркгейм заявляют, что публичная политика создает социальную реальность, которая опирается на трех относительно автономных агентов: политику, социальные науки и журналистику. Профессионалы из этих областей выполняют важную конструктивную функцию, они занимаются объяснением социального мира посредством построения и трактования практических схем, придавая последним относительно систематический вид для последующего обсуждения и реализации.

Результаты исследования. Один из подходов к пониманию публичной политики - рассматривать ее как широкую стратегию, которую правительство использует для выполнения своей работы. Если принять более формальную трактовку, то это относительно стабильный набор целенаправленных действий правительства, направленных на решение проблем, волнующих определенную часть общества [7, c. 1-66]. Это трактовка верна, потому что она помогает объяснить, что является публичной политикой, а что нет.

Большинство результатов политики являются производной от значительных дискуссий, компромиссов и уточнений. Дискуссии при

\footnotetext{
${ }^{2}$ Кочанов Ю. Л. Политическая топология: структурирование политической действительности. М.: AdMarginem. 1995. С. 77-89.

${ }^{3}$ Lerner D., Lasswell H. D. (eds). The Policy Sciences: Recent Developments in Scope and Method. Stanford, CA: Stanford University Press, 2019. P. 180.
} 
участии групп интересов, общественности и правительственных учреждений продолжаются в течение многих лет.

В западном мире изучение феномена публичной политики остается популярным направлением. Разнообразие исследовательских перспектив обеспечивается множественностью определений. В основе своей все они в значительной степени произвольны, что создает двусмысленность и вызывает сомнения в правильности выбора методологии. Исходя из того, что процедура выбора методологии требует обоснования, она не просто порождает множество альтернативных подходов, но и позволяет нам оценить их адекватность. Как и любая область междисциплинарных исследований, публичная политика использует широкий спектр концепций и понятий, в основном заимствованных из смежных дисциплин, например, из политологии, социологии и экономики ${ }^{4}$.

К рассмотрению публичного пространства ряд европейских исследователей подходят как к сфере универсализации гражданской солидарности, «в которой постепенно формируется и укрепляется определенный тип единого сообщества... с описаниями демократической идиомы» [8, с. 9-12]. Если публичное пространство активно повторяет политически существующую демократическую общественность, то на основе диалоговых форм общения между различными группами граждан и органами власти она предусматривает практическую реализацию обсуждаемых вопросов.

Применение консультативной политики осложняется рядом ограничений, которые она накладывает на включение публичных субъектов в процесс дискурсивного координирование интересов в ходе принятия решений: Во-первых, субъекты должны обладать взаимностью и готовностью изменить свое отношение к рациональной аргументации, т.е. «коммуникативной компетентностью» [9, с. 35-36]; Во-вторых, вовлечение субъектов в консультативные дискуссии создает их заинтересованность в решении общественных проблем.

С этой стороны публичная сфера представляет собой единое информационно-дискурсивное условие политического пространства, которое способствует увеличению сложности политического процесса за счет добавления в него различных публичных субъектов, что порождает условия для воздействия на них, на процесс принятия по-

\footnotetext{
${ }^{4}$ Лобанова Е. А. Этнические и расовые отношения в Соединенных Штатах Америки: проблемы государственного управления. М., 2004. С. 11-12.
} 
литических решений в основе которых лежат демократические процедуры [10, с. 147-174].

Следовательно, политические субъекты с определенным политическим весом проявляют себя в публичной сфере, осуществляя публичные действия различной степени независимости в условиях открытости и прозрачности взаимодействуя между собой.

Вовлечение различных субъектов в публичную сферу, их независимость и активность в осуществлении стратегий гражданских и политических действий напрямую связаны с проблематикой выделения концепта публичной политики. Основной вопрос заключается в том, что такое публичная политика, функционирует ли государство в публичном пространстве, или речь идет о коллективных эффектах деятельности правительства, граждан и фабрик мысли в процессе принятия политических решений?

Актуализация публичной политики как государственного управления осуществляется практически на основе демократических взглядов, принципов и процедур, что характерно для национальной политической системы США, где сильны как демократические общественные и политические традиции, так и развиты традиционные институты политического представительства, а эффективность и действенность решений редко ставится под сомнение $[11$, с. 6].

В европейских научных дискуссиях о публичной политике и качестве государственных решений на реализацию общественных потребностей, была заложена основа для нового подхода к анализу публичной политики. Этот метод призван не только учитывать эффективное перераспределение общественных благ между различными группами населения, но и использовать методы «согласования интересов и достижения эффективного результата, максимизируя общественную полезность» $[12$, с. 76$]$.

В европейской традиции публичная политика включает в себя:

- предметную область принятия решений, формирующуюся в публичной сфере;

- государственные и негосударственные субъекты, взаимодействующие в процессе принятия решений на различных уровнях управления (национальном, региональном, местном);

- формы, методы и технологии участия, связанные с единым политическим контекстом [13, с. 15-58].

В связи с этим концепция публичной политики выходит за рамки государства и предусматривает вовлечение различных обществен- 
ных групп, государственных и негосударственных субъектов в политический и управленческий процесс на основе различных механизмов согласования интересов и культуры консенсуса. Здесь предполагается учитывать следующие компоненты, влияющие на процесс разработки и реализации политического курса:

согласование интересов в форме дискурсивных практик в публичной сфере, с помощью которых актуализируются социально значимые проблемы, потребности, конфликты;

• институциональные (институты, формальные правила и процедуры) и когнитивные условия (схемы и ценности) генезиса публичных действий со стороны общественности (институты гражданского общества, общественные лидеры, средства массовой информации, бизнес - структуры) и политических субъектов (политические партии, группы интересов и давления, политические лидеры), а также инклюзивные механизмы их координации перед прямыми политическими действиями правительства;

- наличие неиерархических структур (коалиций или сетей), имеющих как общественные организационные надстройки, так и скрытые связи, в рамках которых осуществляется координация публичных действий различных субъектов (государственных и негосударственных) и разработка коллективного курса политических действий;

институциональный уровень доверия в обществе, выражающийся в поддержке общественными и политическими субъектами, населением страны в целом деятельности властей и признании их легитимными.

Одним из ключевых механизмов, ведущих к информационнодискурсивным и управленческим «оболочкам» публичной политики, является обратная связь. Этот механизм представляет собой коммуникативное взаимодействие государственных органов, институтов гражданского общества, средств массовой информации и бизнес структур, в результате которого эффективность принимаемых решений оценивается в соответствии с общественными потребностями [14, c. 230-237]. Обратная связь характеризуется технологиями и формами общественности (общественная экспертиза, общественное мнение, общественный контроль и т. д.) [15, с. 2-10]. Участие в этом процессе общественности предполагает взаимодействие различных групп и сторон, которые заинтересованы в решении проблем сообщества, решении сложных вопросов путем совместного обсуждения и разработ- 
ки решений и достижения соглашения по этим вопросам как в процессе диалога с властями, так и внутри сообщества.

В рамках многообразных технологий и форм общественного и гражданского участия неофициальные субъекты интегрируются в профессиональную и управленческую деятельность государственных структур, тем самым реализуя материальный (денежный) капитал общества. Важно, что без активного участия государства невозможно расширить воздействие институтов гражданского общества на решение управленческих задач.

Правительство создает условия для реального влияния граждан и институтов гражданского общества на принятие государственных и политических решений путем расширения открытости и прозрачности деятельности государственных органов, повышения стандартов качества государственного управления, предоставления доступных и качественных государственных услуг населению на всей территории, повышения благосостояния населения и усиления поддержки и доверия населения к государству как к координатору и организатору, лидеру коллективных социальных действий. Разработка публичной политики оказывается важным показателем способности правительства эффективно управлять.

В дополнение к тому факту, что публичная политика хорошо продумана и в целом стабильна, она затрагивает вопросы, которые касаются всех слоев общества, в отличие от вопросов, представляющих интерес только для отдельных лиц или небольшой группы людей. Они могут даже принимать узкоспециализированные законодательные акты, известные как частные законопроекты, которые предоставляют определенные привилегии отдельным организациям. Погашение кредитов конкретного человека не будет публичной политикой, но создание процесса прощения кредитов, доступного для определенных категорий заемщиков (например, тех, кто предоставляет государственные услуги, став учителями), несомненно, поднимется до уровня публичной политики [16, с. 619-631].

Последней важной характеристикой публичной политики является то, что она представляет не только действия правительства, но и результаты, созданные его действиями. Политика может быть разработана даже тогда, когда правительство отказывается действовать таким образом, чтобы изменить статус-кво, когда обстоятельства или общественное мнение начинают меняться. 
В связи с этим можно рассматривать политику как формальное выражение того, что пытаются достичь избранные или назначенные должностные лица. Хотя политические заявления и бюрократические действия, безусловно, направлены на рационализацию политики, именно ее успешность в конечном счете определяет, как электорат будет реагировать на правительство на будущих выборах [17, с. 155170]. Избиратели оценивают публичную политику по ее результатам. Даже обдуманная политика может иметь непредвиденные последствия и в конечном итоге нанести вред кому-то.

В результате, публичная сфера может стать полем для распространения ложной информации, мнимых ценностей, ложных образов и других форм имитации интересов, которые в конечном итоге формируют искусственные диспозиции государства и общества. И хотя в этом качестве публичность как особая форма социального пространства больше не является ограничителем возможностей политических субъектов, тем не менее, она оставляет государству широкие возможности для вытеснения своих гражданских оппонентов из открытых коммуникаций.

Наиболее подходящей основой для аналитического осмысления «параметров» публичной политики является концепция политической воли. Ведь она отражает триединство целей всех участников публичной политики, их реальное положение в пространстве власти (характеризующее их близость к центрам принятия решений), а также формы их фактического взаимодействия, определяющие разработку целей публичной политики. Вследствие волевых причин публичность связана с целенаправленными действиями субъектов, которые посвоему влияют на содержание публичной политики, способствуют преодолению препятствий, готовности к рискам, совместным формам управления и т.д. Более того, использование понятия политической воли позволяет не только фиксировать фактические проявления открытых форм деятельности политических субъектов, которые зависят от «контекста политической жизни», но и выявлять «невидимую волю субъектов, борющихся за власть (в том числе, если она узурпирована элитой или публичная политика не является успешной или популярной с самого начала» [18, с. 40].

В своем волевом измерении публичность отражает только политическую энергию действующих лиц, которые проявляют свои интересы, вынося в открытое политическое пространство цели, побуждающие оппонентов (сторонников) реагировать, способствовать уста- 
новлению выгодных коммуникаций, провоцировать общественный резонанс. Сохраняя риски конкуренции и издержки асимметричного отношения к центрам власти, концепция публичности в то же время противостоит скрытым формам политической воли (тайным заговорам, внутриэлитным сделкам, закулисным соглашениям и т.д.).

Понимание власти как «присвоения чужой воли» одновременно позволяет в рамках онтологизации исторического опыта определить функциональность публичности [19, с. 185-188]. В этой связи уместно напомнить, что немецкий философ и социолог Ю. Хабермас первым предложил провести различие между сильными и слабыми публичными сферами. Хотя речь шла в основном об информационном пространстве, следует признать, что немецкие философы методологически одобрили нетривиальное понимание неоднородности публичной политики в силу ее различных проявлений.

Подход, направленный на понимание различных способов самораскрытия публичности в сферах государственной деятельности (и, следовательно, выявление неоднозначных критериев оценки ее властного потенциала), демонстрирует невозможность сведения ее роли к однозначно позитивным и легитимным формам взаимодействия государства и общества ${ }^{5}$. С учетом пространственной диверсификации публичности, априори становится невозможным определить масштабы, характер и даже вектор ее политической ориентации (тем самым однозначно отвечая на вопрос, может ли дискуссия изменить политический статус общественности, или заявить, что политическая инициатива принадлежит государству, а общество всегда играет второстепенную роль).

Смещение фокуса публичной политики зависит от комплекса решаемых задач и мотивации элит и масс (включая их заинтересованность в совместных действиях), которые развиваются в определенных социальных пространствах в организме государства ${ }^{6}$. Именно это определяет формат общественных отношений между властью и обществом, накладывает ограничения на использование политическими игроками открытых форм общения.

\footnotetext{
5 Андерсон Дж. Публичная политика: Введение // Публичная политика: от теории к практике / сост. и науч. ред. Н. Ю. Данилова, О. Ю. Гурова, Н. Г. Жидкова. СПб.: Алетейя, 2008. С. 356-358.

${ }^{6}$ Сунь Дасюн. Zheng zhi hu dong : li yi ji tuan yu mei guo zhenf fu de jue ce = Политическое взаимодействие: Группы интересов и принятие решений правительством США : дис. ...кандидата полит. наук: 23.00.01. Хубэй. 2002. С. 77.
} 
Публичная политика на современном этапе (с начала XXI в.) рассматривает людей как активных участников управления, а не как простые экономические единицы.

Заключение. Изначально изучение публичной политики в Соединенных Штатах отличалось и от европейских подходов, когда наука публичной политике рассматривалась как тип административного права, и от изучения публичной политики как синтеза элементов политологии, административного права, социологии. Развитие науки о публичной политике в США исходило из представления о ней как о дисциплине, имеющей не только теоретический, но и, главным образом, практический и прикладной характер, призванный улучшить функционирование администрации, профессионализацию государственного аппарата, его отделение от политики.

Именно поэтому развитие научной области публичной политики шло в двух основных направлениях: анализ практики публичной политики и разработка теории с учетом этой практики, что стало ключевым отличием от европейской системы, которая до этого этапа в большей степени основывалась на теоретических подходах к управлению инструментами публичной политики.

Публичная политика стран ЕС в научно-технической сфере реализуется с помощью различных инструментов, таких как законодательство, налоговая политика, размер и характер распределения бюджетных средств, в том числе для проведения работ по приоритетным направлениям, формирование и поддержание инфраструктуры, кадрового обеспечения. Удельный вес и роль определенных инструментов в отдельных странах различаются.

Таким образом, изучение зарубежного опыта стран, которые заложили теоретические основы и разработали инструментарий публичной политики, представляет значимый интерес. Усложнение структуры современного общества требует пересмотра и во многом модернизации подходов к процессу коммуникации по линии государство - общество. Растущий интерес граждан к политической сфере заметно повышает их требования, которые направлены, прежде всего, на расширение круга лиц, принимающих участие в процессе принятия решений. Вместе с тем необходимо понимать, что простое копирование удачных примеров в сфере публичной политики будет скорее означать провал, нежели повторение успеха. Как и в любом другом процессе, учет национальной специфики является ключевым факто- 
ром в имплементации тех или иных подходов к сфере государственного управления.

Благодарности. Автор выражает признательность China Scholarship Council за оказанную поддержку при проведении данного исследования. Благодарит своего научного руководителя Лазоркину Ольгу Игоревну за рекомендации в проведении научного исследования.

\section{Библиографические ссылки}

1.Чжан Цзинма. Гун гун чжэн цэ: Сюэ кэ дин вэй юй гэ нянь фэ си = Публичная политика: предметное позиционирование и концептуальный анализ // Пекинский институт управления, 2000. № 1. C. 8-11.

2. Петухов B. B. Гражданское общество и демократия участия // Мониторинг общественного мнения. 2006. № 1 (77). С. 3-5.

3. Stone D. L. Transfer agents and global networks in the "transnationalisation" of policy // Journal of European Public Policy. 2004. № 11 (3), p. 545-566.

4. Хабермас Ю. Отношения между системой и жизненным миром в условиях позднего капитализма // Thesis.1993. № 1. С. 120-125.

5. Шматко Н. А. Феномен публичной политики // Социологические исследования. 2001. № 7. C. $110-115$.

6. Якимец B. Н. Международное социальное партнерство: основы, теория, принципы, механизм. М.: УРСС, 2004. С. 377-382.

7. Atkinson A. B. Incomes and the Welfare State: Essays on Britain and Europe. London: Cambridge University. 2015, p. 1-66.

8. Capano G. European and North American Experiences in Policy Change. Policy Drivers and Policy Dynamics. London: Routledge. 2009, p. 9-12.

9. Гимпель Л. П. Модель развития коммуникативной компетентности студентов // Вышэйшая школа. 2010. № 2. С. 35-36.

10. Overbye E. Convergence in policy outcomes: Social security systems in perspective // Journal of Public Policy. 2014. № 14, p. 147-174.

11.Ян Рунгуан. Интерпретация взгляда Америки на демократию и демократические институты // Документ с красным флагом. 2013. № 08. С. 6.

12. Беляева Н. Ю. Развитие концепта публичной политики : Внимание «движущим силам» и управляющим субъектам // Полис. Политические исследования. 2011. № 3. С. 76.

13. Kühner S. Country - level comparisons of welfare state change measures: Another facet of the dependent variable problem within the comparative analysis of the welfare state // Journal of European Social Policy. 2007. № 17, p. 15-58.

14. Schmitt S. Comparative approaches to the study of public policy-making. Oxford. 2018, p. 230237 .

15. Хомутова О. Ю. Общественный контроль как механизм обратной связи // Вестник РУДН. 2014. № 4. C. 2-10.

16. Habermas J. Between Facts and Norms. London: Cambridge University. 1996, 631 p.

17. Кокошин А. А. Очерк политики как феномена общественной жизни. М.: Культурная революция, 2008. С. 155-170.

18. Тультический Г. Л. Политическая воля: Феномен и концепт // Наследие. № 1 (10). 2017. C. 40.

19. Соловьев А. И. Фронтирные зоны публичной политики // Political science. 2021. № 3. C. $185-188$.

Дата поступления статьи: 21.09.2021. 
Автор - Ян Кэ, аспирантка кафедры дипломатической и консульской службы факультета международных отношений белорусского государственного университета; email: yangke151617@gmail.com.

\title{
PUBLIC POLICY IN THE USA AND THE EU: THEORETICAL APPROACHES
}

\section{Yang Ke \\ Belarusian State University, Minsk, Republic of Belarus}

\begin{abstract}
The article, examining the development of the main branches of public policy in the United States and some countries of continental Europe, reveals the main characters and processes of the functioning of public policy in the United States and the largest EU countries.

Various interpretations of the term - public policy, from political scientists representing different political schools. The source of a variety of definitions in the field of various social sciences, concepts and society was analyzed, in which different methodologies of public policy were considered.

In the process of analyzing the interpretation of public policy in the United States and the EU, three approaches to understanding the term public policy have been identified: institutional, activity and academic.

In order to analyze and systematize the main approaches to understanding public policy used in the US and the EU, the method of analysis, comparison and generalization was used.

The main idea of the approach, in which civil society is viewed as the main element of public policy, is to try to be involved in the process of the political life of one's country, not by the force of external factors, but by self-awareness. So the people of the country are themselves turning into a political element. In response to this behavior, the US and EU are encouraging citizens to participate in political life. This process forces society to make high demands on public policy.

This article presents the results of a descriptive and comparative description of the approaches of the US and the EU to public policy, as a generalized material and identifies the key points for the implementation of certain approaches in the field of public administration.
\end{abstract}

Key words: public policy; Europe; USA; electoral system; legal system; political and institutional forces; social policy; innovative development.

For citation: Yang Ke (2021). Publichnaya politika v SSHA i ES: teoriticheskie podhody [Public policy in the USA and the EU: Theoretical appoaches]. In: Actual problems of international relations and global development: collection of scientific articles. Minsk, Vol. 9, p. 289-302. https://doi.org/10.33581/2311-9470-2021-9-289302 


\section{References}

1. Zhang Jinma. Gong gong zheng ce: Xue ke ding wei yu gai nian fen xi [Public Policy: subject positioning and conceptual analysis]. Beijing Institute of Management, 2000. № 1, p. 8-11. (In Chin.).

2. Petuhov V. V. Grazhdanskoe obshestvo I demokratia uchastia [Civil society and participatory democracy]. In: Monitoring obshestvennogo mnenia. 2006. № 1 (77), p. 3-5. (In Russ.).

3. Stone D. L. Transfer agents and global networks in the "transnationalisation" of policy. In: Journal of European Public Policy. 2004. № 11 (3), p. 545-566.

4. Habermas Yu. Otnoshenia mezhdu sistemoy i zhiznennym mirom v usloviyh pozdnego kapitalizma [The relationship between the system and the life - world in the conditions of late capitalism]. In: Thesis. 1993. № 1, p. 120-125. (In Russ.).

5. Shmatko N. A. Fenomen publichnoy politiki [The Phenomenon of Public Policy]. In: Sociologicheskie issledovania. 2001. № 7, p. 110-115. (In Russ.).

6. Yakimec V. N. Mezhdunarodnoe socialnoe partnerstvo: osnovy, teoria, principy, mechanism. [International social partnership: foundations, theory, principles, mechanism]. London: Cambridge University, 2004, p. 377-382. (In Russ.).

7. Atkinson A. B. Incomes and the Welfare State: Essays on Britain and Europe. London: Cambridge University. 2015. p. 1-66.

8. Capano G. European and North American Experiences in Policy Change. Policy Drivers and Policy Dynamics. London: Routledge. 2009, p. 9-12.

9. Gimpel L. P. Model razvitia kommunikativnoy kompetentnosti studentov [Model of development of students' communicative competence]. In: Vysheyshaya shkola. 2010. № 2, p. 35-36. (In Russ.).

10. Overbye E. Convergence in policy outcomes: Social security systems in perspective. In: Journal of Public Policy. 2014. № 14, p. 147-174.

11. Yan Runguan. Interpretacia vzglyada Ameriki na demokratiyu i demokraticheskie instituty [Interpreting America's View of Democracy and Democratic Institutions]. In: Dokument s krasnym flagom. 2013. № 8, p. 6. (In Russ.).

12. Belyaeva N. U. Razvitie koncepta publichnoy politiki: Vnimanie "dvizhushim silam" i upravlyaushim subyektsm [Development of the concept of public policy: Attention to "driving forces" and governing actors]. In: Polis. Politicheskie issledovaniya. 2011. № 3, p. 76. (In Russ.).

13. Kühner S. Country- level comparisons of welfare state change measures: Another facet of the dependent variable problem within the comparative analysis of the welfare state. In: Journal of European Social Policy. 2007. № 17, p. 15-58.

14. Schmitt S. Comparative approaches to the study of public policy-making. Oxford. 2018, p. 230237.

15. Homutova O. U. Obshestvenny kontrol kak mehanizm obratnoy svyazi [Public control as a feedback mechanism]. In: Vestnik RUDN. 2014, № 4, p. 2-10. (In Russ.).

16. Habermas J. Between Facts and Norms. London: Cambridge University. 1996. 631 p.

17. Kokoshin A. A. Ocherk politiki kak phenomena obshestvennoy zhizny [Essay on politics as a phenomenon of public life]. Moscow. 2008, p. 155-170. (In Russ.).

18. Tulticheskiy G. L. Politicheskaya volya: Fenomen i concept [Political will: Phenomenon and Concept]. In: Nasledie. № 1 (10). 2017, p. 40. (In Russ.).

19. Soloviev A. I. Frontirnye zony publichnoy politiki [Frontier zones of public policy]. In: Political science. 2021. № 3, p. 185-188. (In Russ.).

Received: 21.09 .2021 .

About author: Yang Ke - PhD Student, Department of Diplomatic and Consular Service, Faculty of International Relations, Belarusian State University; email: yangke151617@gmail.com. 